\title{
Impedance fluctuation and steam pop occurrence during radiofrequency current ablation: An experimental in vitro model
}

\author{
Rafał Olszewski ${ }^{1, A, B, D, F}$, Paweł Ptaszyński ${ }^{2, A-C, E, F}$, Iwona Cygankiewicz ${ }^{2, A, E, F}$, Krzysztof Kaczmarek ${ }^{2, A-C, E}$ \\ ${ }^{1}$ Department of Cardiology, St. Adalbert's Hospital, Gdańsk, Poland \\ 2 Department of Electrocardiology, Medical University of Lodz, Poland \\ A - research concept and design; $B$ - collection and/or assembly of data; $C$ - data analysis and interpretation; \\ $D$ - writing the article; $E$ - critical revision of the article; $F$ - final approval of the article
}

\author{
Address for correspondence \\ Krzysztof Kaczmarek \\ E-mail: krzysztof.kaczmarek@umed.lodz.pl \\ Funding sources \\ None declared
}

Conflict of interest

None declared

Received on March 6, 2021

Reviewed on May 11, 2021

Accepted on May 12, 2021

Published online on October 5, 2021

Cite as

Olszewski R, Ptaszyński P, CygankiewiczI, Kaczmarek K. Impedance fluctuation and steam pop occurrence during radiofrequency current ablation: An experimental in vitro model. Adv Clin Exp Med. 2021;30(10):1051-1056. doi:10.17219/acem/136845

DOI

10.17219/acem/136845

Copyright

Copyright by Author(s)

This is an article distributed under the terms of the

Creative Commons Attribution 3.0 Unported (CC BY 3.0)

(https://creativecommons.org/licenses/by/3.0/)

\begin{abstract}
Background. The radiofrequency impedance measurement is one of the basic parameters monitored during ablation procedures. An abrupt rise in impedance is often observed corresponding to a steam pop. The exact correlation between the occurrence of steam pop and subsequent rise in impedance has not been experimentally described so far.
\end{abstract}

Objectives. To evaluate the relationship between steam pop occurrence and impedance fluctuations observed during radiofrequency ablation (RFA).

Materials and methods. Porcine heart tissue specimens were appropriately prepared and placed in an experimental setup connected to electrophysiological equipment with 3D anatomical mapping facilities. The RFA lesions were performed in standardized conditions with the use of contact force measurement-enabled open irrigation ablation catheter (ThermoCool SmartTouch ${ }^{\top \mathrm{TM}}, 3.5 \mathrm{~mm}$ tip, F-J curvature; Biosense Webster, Irvine, USA) in the power-control mode. The RFA delivery was stopped when the steam pop occurred. Time taken for the steam pop to occur and to the subsequent abrupt impedance rise was recorded, along with the impedance fluctuations during an application.

Results. In total, 25 experimental radiofrequency (RF) current deliveries ended up with steam pops, which occurred after 30-60 s. The time recorded from the beginning of the application up to the steam pop was shorter if increased power was applied ( $35 \mathrm{~W}$ compared to $30 \mathrm{~W}: 41.5 \pm 9.9 \mathrm{~s}$ compared to $49.9 \pm 8.2 \mathrm{~s}$; $p=0.046)$. During all RF applications, impedance significantly but gradually decreased from $122.9 \pm 7.9 \Omega$ to $87.5 \pm 3.6 \Omega(p<0.001)$ with a mean drop rate of $0.8 \pm 0.2 \Omega / s$. During all experiments, the abrupt and significant impedance increase $(8.2 \pm 2.0 \Omega, p<0.001)$ was observed always after steam pop occurrence (207.4 $\pm 155.9 \mathrm{~ms})$.

Conclusions. During RF current delivery which ended up with steam pop, an abrupt impedance increase was always registered after the occurrence of this phenomenon. Therefore, the impedance rise observed during steam popping cannot be used for its prediction. The time to steam pop was shorter for applications with increased power but not with greater contact force.

Key words: impedance, radiofrequency ablation, tamponade, steam pop, ablation complication 


\section{Background}

Radiofrequency catheter ablation (RFA) is currently the most common technique used for invasive treatment of a wide variety of arrhythmias. Despite growing understanding of the biophysics of radiofrequency current (RFC) delivery, the procedure is still associated with some degree of risk, and steam pops are one of the most threatening complications. $^{1-3}$

Radiofrequency ablation destroys myocardial tissue through thermal injury. Resistive heating occurs in a small zone adjacent to the catheter tip, while the surrounding myocardium is passively heated by conduction. Tissue temperatures above $50^{\circ} \mathrm{C}$ are necessary to produce irreversible coagulation necrosis. Steam pops result from excessive intramyocardial heating when the temperature exceeds $100^{\circ} \mathrm{C}$. In such cases, steam is formed and trapped inside the myocardium. A violent tissue rupture occurs when the steam pressure destroys the structural integrity of the cardiac muscle. ${ }^{4,5}$ Steam pops can lead, in the worst cases, to uncontrolled cardiac perforation and the clinical sequelae of cardiac tamponade. ${ }^{6}$ Steam pop incidence complicating up to $1.5 \%$ of RFA procedures has already been a subject of several studies. ${ }^{7-18}$ Different parameters have been analyzed to predict the occurrence of steam explosions, including classical and novel tools. ${ }^{3,5,10,19-29}$ An abrupt impedance rise is one of the most widely described physical phenomena accompanying RFA complicated by steam popping. 3,10,12

\section{Objectives}

As it has never been characterized precisely enough, the aim of our in vitro experiment was to evaluate the timing of impedance fluctuations related to steam pop occurrence to establish its predictive potential in such complications.

\section{Materials and methods}

\section{Experimental setup}

The experimental setup consisted of a transparent container with a sample-holder table and electrical connections necessary to use electrophysiological ablation catheters. Three hearts (weighing 310 g, 340 g and 320 g, respectively) excised by a local abattoir from healthy pigs (Sus scrofa) approx. 6 months of age were used (within $6 \mathrm{~h}$ from slaughtering) to prepare 3 separate cuboid samples (dimensions: $70 \mathrm{~mm}$ wide, $80 \mathrm{~mm}$ long and $15 \mathrm{~mm}$ thick). The samples were immersed in saline $(0.9 \% \mathrm{NaCl})$, which, to approximate physiologic conditions, was heated up to $37 \pm 2^{\circ} \mathrm{C}$ and diluted to generate an ablation circuit impedance value within a range of $80-120 \Omega$. Electrical connections included indifferent RFA electrode located underneath the sample-holding table and connected to radiofrequency (RF) current generator (Stockert $70 \mathrm{RF}^{\mathrm{TM}}$ Generator; Stockert GmbH, Freiburg im Brisgau, Germany), electroanatomic reference patches and a reference pad connected to the 3D electroanatomic environment (CARTO $^{\mathrm{TM}}$; Biosense Webster Inc., Johnson and Johnson Medical, NV/SA, Waterloo, Belgium). Contact force measurement-enabled open irrigation ablation catheter (ThermoCool SmartTouch ${ }^{\mathrm{TM}}$, $3.5 \mathrm{~mm}$ tip, F-J curvature; Biosense Webster, Inc., Johnson and Johnson Medical, NV/ SA) was used to create ablation lesions. The catheter attachment enabled bidirectional movement of its distal part to achieve the planned target contact force value (Fig. 1). Steam pops were identified with a contact microphone (CM200 ${ }^{\mathrm{TM}}$; Korg, Tokyo, Japan) placed in a saline solution close to the sample table, and connected to the electrophysiological recording system (EP Tracer ${ }^{\mathrm{TM}}$; Schwarzer Cardiotek GmbH, Heilbronn, Germany) in a bipolar configuration. Steam pop generated an acoustic wave, which was recorded using an immersed contact microphone and presented as a sharp electrogram by both electrophysiological and electroanatomical systems. The RealGraph ${ }^{\mathrm{TM}}$, module of the CARTO ${ }^{\mathrm{TM}}$ system, allowed simultaneous presentation of the RFA impedance curve and the spike corresponding to the moment of steam pop occurrence (Fig. 2).

\section{Experimental protocol}

Before lesion formation, an electroanatomical model of porcine heart tissue specimen was prepared. The RFA was performed in a power-control mode with 2 different energy settings: $30 \mathrm{~W}$ and $35 \mathrm{~W}$. These 2 power settings were selected as they were the most commonly used power settings in our centers (35 W was applied for RF applications in the ventricles, the right atrium and non-posterior wall application in the left atrium; $30 \mathrm{~W}$ was used in RF applications in the posterior wall of the left atrium). To allow efficient RFC delivery, catheters were irrigated at a flow rate recommended by the manufacturer depending on the ablation power settings: $20 \mathrm{~mL} / \mathrm{min}$ for the power of $30 \mathrm{~W}$ and $30 \mathrm{~mL} / \mathrm{min}$ for $35 \mathrm{~W}$. Two different contact force levels were maintained, i.e., $20 \pm 5$ g and $30 \pm 5$ g. Continuous measurements of power, impedance and contact force were recorded for each RF ablation. The RFC delivery duration was limited to the steam pop occurrence. The time from the beginning of energy application to the steam pop occurrence, as well as the time to impedance fluctuations were recorded with the accuracy of $1 \mathrm{~ms}$. Additionally, an impedance change was measured as the difference between the maximum impedance after the steam pop and the impedance just before this event. Having determined the power value and the time of application, energy 

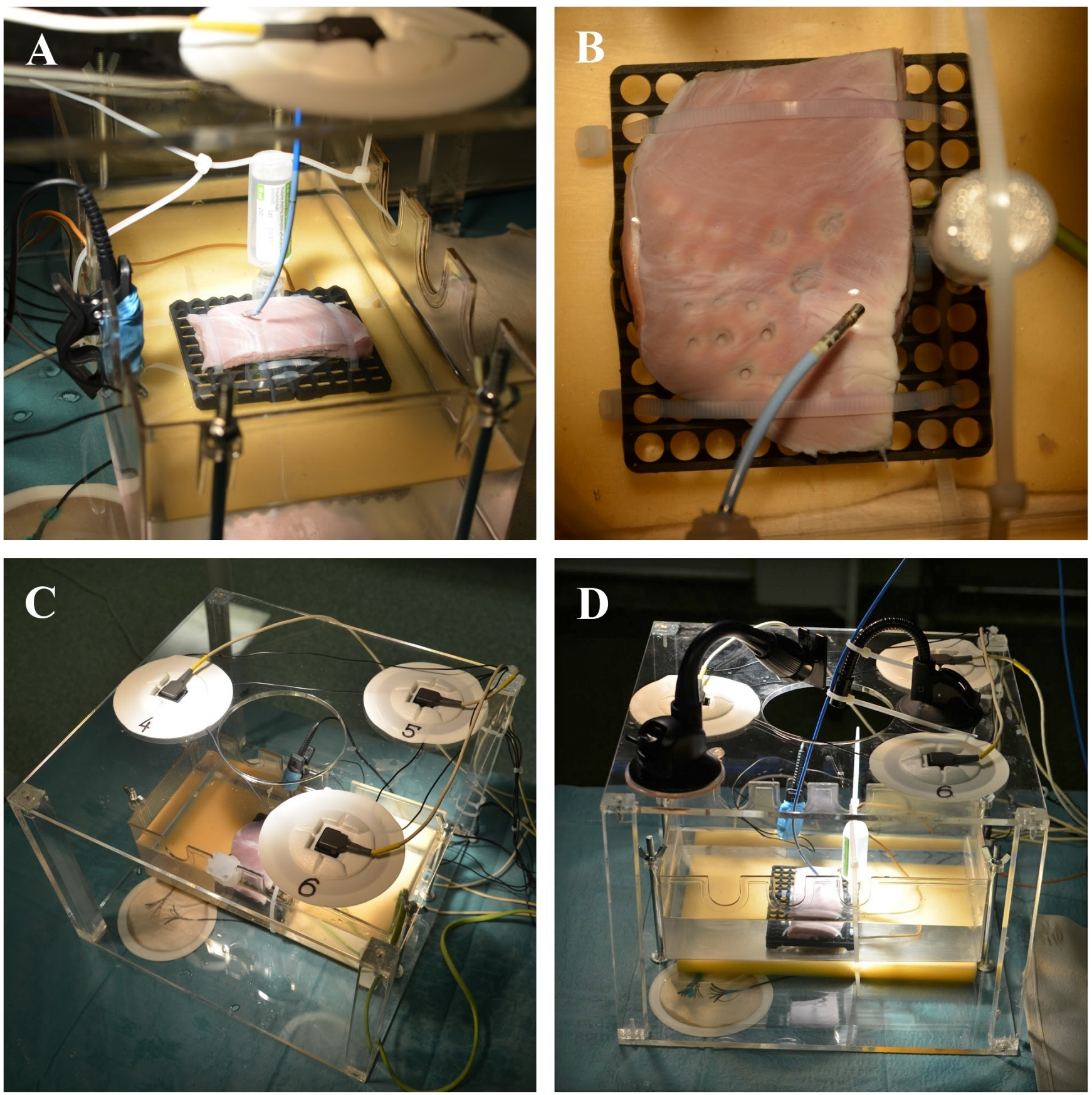

Fig. 1. Experimental setup. $A$ and B. Porcine heart tissue specimen attached to a sample-holding table; $C$ and $D$. Wet-lab bathtub inside a cuboid cage equipped with electroanatomic reference patches

delivered to the tissue was calculated following a standard equation (energy $[\mathrm{J}]=$ power $[\mathrm{W}] \times$ time $[\mathrm{s}]$ ). The temperature registered on the catheters just before steam pop was also recorded. After each steam pop occurrence, the ablation catheter was moved to another location where the new lesion was created.

As our study was purely experimental, without the participation of any humans nor any living organisms, the investigators waived approval of a bioethical committee. For the same reasons, the Declaration of Helsinki was also not applicable to our research.

\section{Statistical analyses}

Statistical analyses were performed using Statistica software v. 13 (StatSoft Inc., Tulsa, USA). Continuous variables were tested for normality with the Shapiro-Wilk test and presented as mean \pm standard deviation (SD) and median (interquartile range (IQR)). Categorical variables were given as numbers and percentages. When 2 groups were compared, either the Student's test or the Mann-Whitney $\mathrm{U}$ test was used according to the data distribution. Values of $\mathrm{p}<0.05$ were considered statistically significant. 


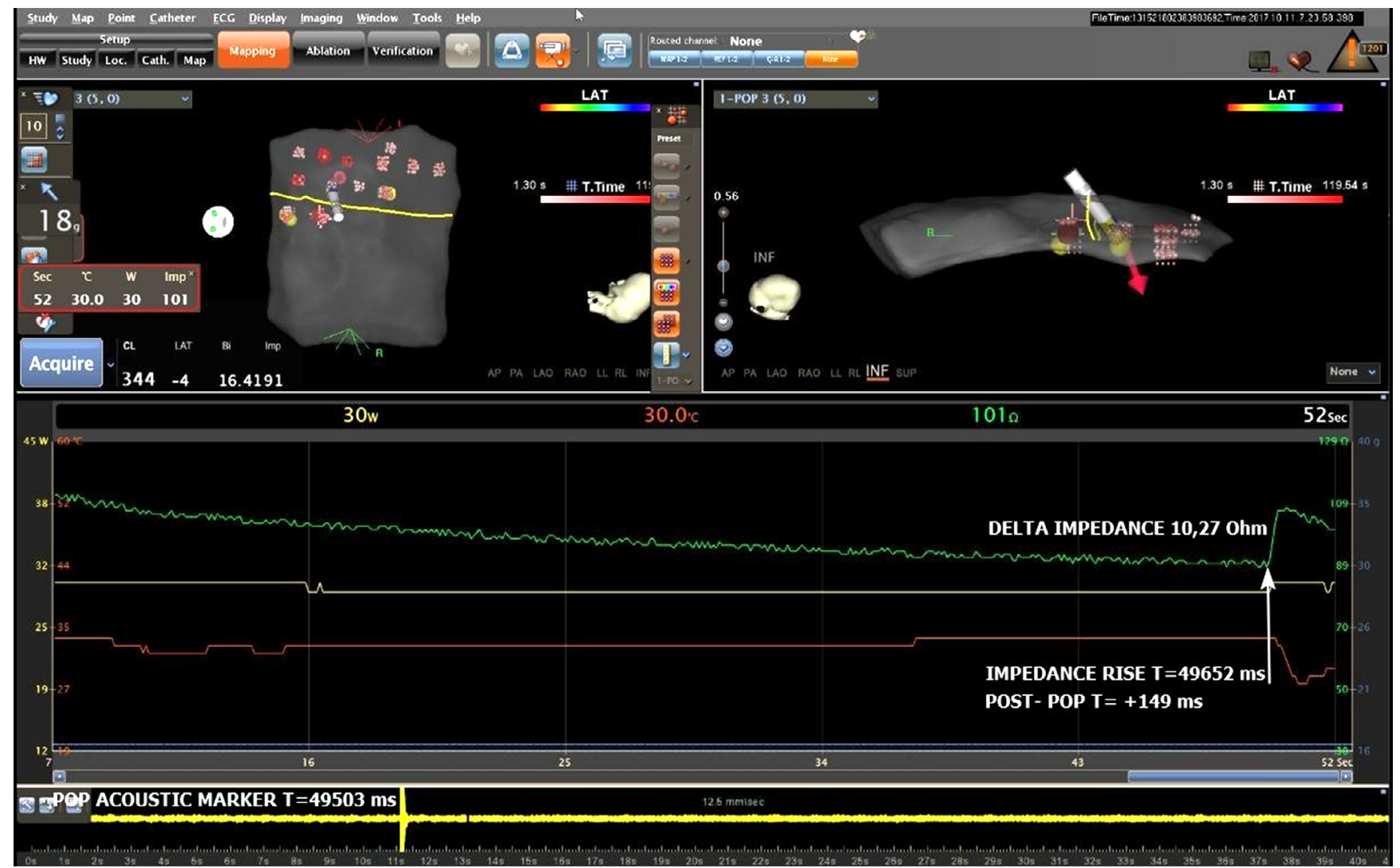

Fig. 2. Sample of measurements performed during experimental radiofrequency ablation (RFA). Acoustic marker T - steam pop occurrence time (data from the contact microphone connected to the electrophysiological system); delta impedance - the impedance rise value; impedance rise $T$ - impedance abrupt rise time; post-pop T - steam pop and impedance rise time difference

\section{Results}

In total, 25 experimental RFC deliveries which ended up with steam pops were performed. All the investigated events occurred after approx. 30-60 s (Table 1). The time from the beginning of the application up to the steam pop recording was shorter if increased power value was set (35 W compared to $30 \mathrm{~W}: 41.5 \pm 9.9 \mathrm{~s}$ compared to $49.9 \pm 8.2 \mathrm{~s} ; \mathrm{p}=0.046$ ); however, the amount of energy delivered was similar for both subgroups ( $35 \mathrm{~W}$ compared to $30 \mathrm{~W}: 1453.7 \pm 346.9 \mathrm{~J}$ compared to $1496.2 \pm 246.3 \mathrm{~J} ; \mathrm{p}=0.7$ ). There was no significant difference in the time to steam pop in applications with distinct contact force $(20 \mathrm{~g}$ compared to $30 \mathrm{~g}$ : $47.7 \pm 11.3 \mathrm{~s}$ compared to $44.3 \pm 7.5 \mathrm{~s} ; \mathrm{p}=0.4$ ). During all RFC applications, the impedance significantly decreased from $122.9 \pm 7.9 \Omega$ to $87.5 \pm 3.6 \Omega(\mathrm{p}<0.001)$, which means

Table 1. Characteristics of radiofrequency (RF) current applications

\begin{tabular}{|l|c|c|}
\multicolumn{1}{|c|}{ Parameter } & Mean \pm SD & Median (IQR) \\
\hline Impedance at baseline $[\Omega]$ & $122.9 \pm 7.9$ & $126.0(116-130)$ \\
\hline Impedance at the moment of steam pop $[\Omega]$ & $87.5 \pm 3.6$ & $88.0(85.0-89.0)$ \\
\hline Impedance baseline-steam pop $[\Omega]$ & $35.4 \pm 6.8$ & - \\
\hline Impedance baseline-steam pop [\%] & $28.6 \pm 4.1$ & $27.8(25.8-33.1)$ \\
\hline Rate of an impedance decrease $[\Omega / s]$ & $0.8 \pm 0.2$ & $0.7(0.6-0.8)$ \\
\hline Impedance after steam pop $[\Omega]$ & $8.2 \pm 2.0$ & $7.8(6.9-9.5)$ \\
\hline Impedance after steam pop [\%] & $9.3 \pm 2.3$ & $9.5(7.8-10.7)$ \\
\hline Time to steam pop [ms] & $46,204 \pm 9760$ & $46,687(42,250-51,384)$ \\
\hline Time to impedance increase $[\mathrm{ms}]$ & $46,411 \pm 9793$ & $46,904(42,360-51,705)$ \\
\hline Time from steam pop to impedance increase $[\mathrm{ms}]$ & $207 \pm 1.6$ & $160(97-253)$ \\
\hline Temperature prior to steam pop $\left[{ }^{\circ} \mathrm{C}\right]$ & $33.5 \pm 1.9$ & $34(33-34)$ \\
\hline Energy delivered until steam-pop $[\mathrm{J}]$ & $1477.5 \pm 288.9$ & $1508(1279.6-1600.7)$ \\
\hline
\end{tabular}

$\Delta$ - difference; SD - standard deviation; IQR - interquartile range. 
a $28.6 \pm 4.1 \%$ reduction of the initial value. This impedance drop did not change significantly regardless of the change in ablation power ( $30 \mathrm{~W}$ compared to $35 \mathrm{~W}: 36.1 \pm 6.4 \Omega$ compared to $34.5 \pm 7.6 \Omega ; \mathrm{p}=0.64$ ) and the change in contact force values ( $20 \mathrm{~g}$ compared to $30 \mathrm{~g}: 35.4 \pm 6.8 \Omega$ compared to $35.4 \pm 7.1 \Omega ; \mathrm{p}=1.0$ ). The rate of impedance drop until steam pop amounted to $0.8 \pm 0.2 \Omega / \mathrm{s}$ and did not differ between the applications with lower and increased power (30 W: $0.8 \pm 0.2 \Omega / \mathrm{s}$ compared to $35 \mathrm{~W}: 0.9 \pm 0.3 \Omega / \mathrm{s} ; \mathrm{p}=0.2$ ), neither was it different when distinct contact forces were used ( 20 g: $0.8 \pm 0.2 \Omega / \mathrm{s}$ compared to $30 \mathrm{~g}: 0.8 \pm 0.3 \Omega / \mathrm{s} ; \mathrm{p}=0.6$ ). The other parameters did not differ between subgroups.

During all experiments, a significant and abrupt impedance increase $(8.2 \pm 2.0 \Omega, \mathrm{p}<0.001)$ was observed always after steam pop occurrence. The time difference between the steam pop and the rise in the impedance was insignificantly different between RFC applications with $35 \mathrm{~W}$ compared to $30 \mathrm{~W}(180.1 \pm 113.9 \mathrm{~ms}$ compared to $228.9 \pm 183.8 \mathrm{~ms}, \mathrm{p}=0.4$ ) as well as those performed with distinct contact force ( $20 \mathrm{~g}: 243.9 \pm 187.7 \mathrm{~ms}$ compared to $30 \mathrm{g:} 161.6 \pm 91.3 \mathrm{~ms}, \mathrm{p}=0.2$ ). Analogously, the impedance rise was comparable in these subgroups (power $35 \mathrm{~W}$ : $8.7 \pm 4.0 \Omega$ compared to $30 \mathrm{~W}: 7.7 \pm 2.0 \Omega, \mathrm{p}=0.2$; contact force $20 \mathrm{~g}: 7.6 \pm 2.1 \Omega$ compared to $30 \mathrm{~g}: 8.9 \pm 1.8 \Omega, \mathrm{p}=0.1$ ). The temperature values recorded just before steam pop occurrence never exceeded $42^{\circ} \mathrm{C}$, which proves that irrigation of the catheters was adequate. The results of this experiment are summarized in Table 1.

\section{Discussion}

Our study has identified, for the first time, that the abrupt rise in impedance does not precede steam pop but occurs shortly after. Additionally, we revealed that the time for the steam pop to occur was shorter when increased power values were applied, but it was not the case when a greater contact force was used.

Correct prediction of the possibility of a steam pop that can complicate RFA is clinically useful but challenging. During RFC, the energy delivery impedance gradually decreases with tissue heating, and several studies have observed a significant impedance drop before the steam pops. A higher likelihood of steam pops was reported when impedance decreased by more than $15 \Omega^{10,19,21}$; however, this correlation was too vague to either predict or detect steam pops. ${ }^{3,10}$ While the magnitude of impedance change during ablation is not a good predictor of steam pops, a rate of impedance drop for ablation lesion exceeding $1 \Omega / \mathrm{s}$ is seen as a strong independent predictor of their occurrence. ${ }^{20,21}$ However, in our study, the impedance drop rate of $0.8 \Omega / \mathrm{s}$ was registered, and yet, in all the experiments, steam pops occurred. This could be accounted for by the difference in the experimental conditions in our in vitro study compared to the in vivo environment. In one of our previous experiments, we reduced the rate of steam pops by using cardiac tissue from porcine hearts just after slaughter (within less than $2 \mathrm{~h}$ ) along with a high local fluid flow. ${ }^{30}$ Otherwise, the cardiac tissue might not have had enough potential for energy absorption due to the lack of myocardial perfusion.

An abrupt impedance rise was analyzed in the search for a variable that can predict the occurrence of a steam pop in RFA. In our experiment, all RFC applications were characterized with an impedance rise when steam pops occurred. The precise recording method revealed that the impedance increase did not start before, but shortly after a steam poprelated sound. A potential explanation of this phenomenon may be based on the previously described temperature distribution in the ablated tissue..$^{23,27,30}$ The highest temperature during RFA was recorded up to $3 \mathrm{~mm}$ underneath the tissue surface. ${ }^{5,23,31}$ Therefore, the phenomena related to overheating of deeper myocardium are not registered directly on the surface of the endocardium. The impedance rise probably results not only from transformed properties of the cardiac tissue which are provoked by its rupture but also from the catheter movement into an adjacent area. Consequently, the abrupt impedance rise during RFA cannot be used to predict steam pop occurrence. Furthermore, due to the delayed occurrence, any of its derivatives (impedance rise value, impedance rise ratio) cannot be of much use either.

Some authors point out that applications with increased power and greater contact force are connected to an increased probability of steam pops..$^{10,13,21-25}$ Our experiments revealed that RFC delivery with the power increased by only $5 \mathrm{~W}$ (35 W compared to $30 \mathrm{~W}$ ) resulted in a shorter time to steam pops. Such findings may indirectly suggest that increased power of RFC applications pose a greater risk of tissue overheating. Contrastingly, we found that the contact force was not related to the time of steam pops occurrence. Our outcomes are inconsistent with other available data ${ }^{21-25}$ - most probably due to the relatively minor difference in contact force applied in our experiments (20 g compared to $30 \mathrm{~g}$ ).

\section{Limitations}

The main limitation of our study was the approximation of real-life intracardiac conditions as in vitro settings with the use of porcine cardiac tissue. However, this approach allowed us to control all investigated parameters with high precision.

\section{Conclusions}

During the delivery of a RF current delivery which ended up with steam pop, an abrupt impedance increase was registered always after the occurrence of this phenomenon. Therefore, the impedance rise observed during steam popping cannot be used for its prediction. The time to steam pop was shorter for application with increased power but not when greater contact force was applied. 


\section{ORCID iDs}

Rafał Olszewski (D) https://orcid.org/0000-0001-6506-7482 Paweł Ptaszyński (D) https://orcid.org/0000-0001-6084-7324 Iwona Cygankiewicz (D) https://orcid.org/0000-0003-3006-311X Krzysztof Kaczmarek (D) https://orcid.org/0000-0003-1356-5249

\section{References}

1. Wittkampf FHM, Nakagawa H. RF catheter ablation: Lessons on lesions. Pacing Clin Electrophysiol. 2006;29(11):1285-1297. doi:10.1111/j. 1540-8159.2006.00533.x

2. Wittkampf FHM. When bubbles pop. Pacing Clin Electrophysiol. 2009; 32(7):831-832. doi:10.1111/j.1540-8159.2009.02396.x

3. Cooper JM, Sapp JL, Tedrow U, et al. Ablation with an internally irrigated radiofrequency catheter: Learning how to avoid steam pops. Heart Rhythm. 2004;1(3):329-333. doi:10.1016/j.hrthm.2004.04.019

4. Fassini G, Conti S, Pontone G, Pepi M, Tondo C, Dello Russo A. Tissue characteristics and evolution after steam pop. J Interv Card Electrophysiol. 2015;43(3):313. doi:10.1007/s10840-015-9997-0

5. Thompson N, Lustgarten D, Mason B, et al. The relationship between surface temperature, tissue temperature, microbubble formation, and steam pops. Pacing Clin Electrophysiol. 2009;32(7):833-841. doi:10. 1111/j.1540-8159.2009.02397.x

6. Doppalapudi H, Yamada T, Kay GN. Complications during catheter ablation of atrial fibrillation: Identification and prevention. Heart Rhythm. 2009;6(12 Suppl):S18-S25. doi:10.1016/j.hrthm.2009.07.025

7. Chung FP, Chen SA. Avoiding steam explosions during catheter ablation: "Stopping before popping." J Cardiovasc Electrophysiol. 2013; 24(12):1410-1411. doi:10.1111/jce.12233

8. Cappato R, Calkins H, Chen SA, et al. Worldwide survey on the methods, efficacy, and safety of catheter ablation for human atrial fibrillation. Circulation. 2005;111(9):1100-1105. doi:10.1161/01.CIR.000015 7153.30978.67

9. Tokuda M, Kojodjojo P, Epstein LM, et al. Outcomes of cardiac perforation complicating catheter ablation of ventricular arrhythmias. Circ Arrhythm Electrophysiol. 2011;4(5):660-666. doi:10.1161/CIRCEP. 111.963413

10. Seiler J, Roberts-Thomson KC, Raymond JM, Vest J, Delacretaz E, Stevenson WG. Steam pops during irrigated radiofrequency ablation: Feasibility of impedance monitoring for prevention. Heart Rhythm. 2008;5(10):1411-1416. doi:10.1016/j.hrthm.2008.07.011

11. Cappato R, Calkins H, Chen SA, et al. Prevalence and causes of fatal outcome in catheter ablation of atrial fibrillation. J Am Coll Cardiol. 2009;53(19):1798-1803. doi:10.1016/j.jacc.2009.02.022

12. Haines DE, Verow AF. Observations on electrode-tissue interface temperature and effect on electrical impedance during radiofrequency ablation of ventricular myocardium. Circulation. 1990;82(3):1034-1038. doi:10.1161/01.cir.82.3.1034

13. Hsu LF, Jaïs $P$, Hocini $M$, et al. Incidence and prevention of cardiac tamponade complicating ablation for atrial fibrillation. Pacing Clin Electrophysiol. 2005;28(Suppl 1):S106-S109. doi:10.1111/j.1540-8159. 2005.00062.x

14. Vest JA, Seiler J, Stevenson WG. Clinical use of cooled radiofrequency ablation. J Cardiovasc Electrophysiol. 2008;19(7):769-773. doi:10.1111/ j.1540-8167.2008.01193.x

15. Gaita F, Caponi D, Pianelli M, et al. Radiofrequency catheter ablation of atrial fibrillation: A cause of silent thromboembolism? Magnetic resonance imaging assessment of cerebral thromboembolism in patients undergoing ablation of atrial fibrillation. Circulation. 2010;122(17):1667-1673. doi:10.1161/CIRCULATIONAHA.110.937953
16. Bunch TJ, Asirvatham SJ, Friedman PA, et al. Outcomes after cardiac perforation during radiofrequency ablation of the atrium. J Cardiovasc Electrophysiol. 2005;16(11):1172-1179. doi:10.1111/j.15408167.2005.50135.x

17. Jaïs $P$, Shah DC, Haïssaguerre $M$, et al. Efficacy and safety of septal and left-atrial linear ablation for atrial fibrillation. Am J Cardiol. 1999; 84(9A):139R-146R. doi:10.1016/s0002-9149(99)00714-6

18. Jaïs $P$, Hocini $M, H$ su LF, et al. Technique and results of linear ablation at the mitral isthmus. Circulation. 2004;110(19):2996-3002. doi:10. 1161/01.CIR.0000146917.75041.58

19. Strickberger SA, Ravi S, Daoud E, Niebauer M, Man KC, Morady F. Relation between impedance and temperature during radiofrequency ablation of accessory pathways. Am Heart J. 1995;130(5):1026-1030. doi:10.1016/0002-8703(95)90204-x

20. Koruth JS, Dukkipati S, Gangireddy S, et al. Occurrence of steam pops during irrigated RF ablation: Novel insights from microwave radiometry. J Cardiovasc Electrophysiol. 2013;24(11):1271-1277. doi:10.1111/ jce.12181

21. Nguyen DT, Zipse M, Borne RT, Zheng L, Tzou WS, Sauer WH. Use of tissue electric and ultrasound characteristics to predict and prevent steam-generated cavitation during high-power radiofrequency ablation. JACC Clin Electrophysiol. 2018;4(4):491-500. doi:10.1016/j. jacep.2017.10.003

22. Thiagalingam A, D'Avila A, Foley L, et al. Importance of catheter contact force during irrigated radiofrequency ablation: Evaluation in a porcine ex vivo model using a force-sensing catheter.J Cardiovasc Electrophysiol. 2010;21(7):806-811. doi:10.1111/j.1540-8167.2009.01693.x

23. Yokoyama K, Nakagawa H, Shah DC, et al. Novel contact force sensor incorporated in irrigated radiofrequency ablation catheter predicts lesion size and incidence of steam pop and thrombus. Circ Arrhythm Electrophysiol. 2008;1(5):354-362. doi:10.1161/CIRCEP.108.803650

24. Ikeda A, Nakagawa $H$, Lambert $H$, et al. Relationship between catheter contact force and radiofrequency lesion size and incidence of steam pop in the beating canine heart: Electrogram amplitude, impedance, and electrode temperature are poor predictors of electrode-tissue contact force and lesion size. Circ Arrhythm Electrophysiol. 2014;7(6):1174-1180. doi:10.1161/CIRCEP.113.001094

25. Nakagawa $\mathrm{H}$, Jackman WM. The role of contact force in atrial fibrillation ablation. J Atr Fibrillation. 2014;7(1):1027. doi:10.4022/jafib.1027

26. Chik WWB, Kosobrodov R, Bhaskaran A, et al. Acoustic signal emission monitoring as a novel method to predict steam pops during radiofrequency ablation: Preliminary observations. J Cardiovasc Electrophysiol. 2015;26(4):440-447. doi:10.1111/jce.12598

27. Wright $M$, Harks $E$, Deladi $S$, et al. Visualizing intramyocardial steam formation with a radiofrequency ablation catheter incorporating nearfield ultrasound. J Cardiovasc Electrophysiol. 2013;24(12):1403-1409. doi:10.1111/jce.12218

28. Kondo Y, Ueda M, Kobayashi Y. Visualizing induced silent steam pop with intracardiac echocardiography. Europace. 2017;19(7):1145. doi:10. 1093/europace/eux085

29. Wood MA, Shaffer KM, Ellenbogen AL, Ownby ED. Microbubbles during radiofrequency catheter ablation: Composition and formation. Heart Rhythm. 2005;2(4):397-403. doi:10.1016/j.hrthm.2004.12.026

30. Kaczmarek K, Cygankiewicz I, Strzelecki A, Wranicz JK, Ptaszyński P. In vitro evaluation of new Polish prototypes of 4-mm-tip and 8-mmtip nonirrigated radiofrequency ablation catheters. Kardiol Pol.2020; 78(11):1142-1147. doi:10.33963/KP.15605

31. Yokoyama K, Nakagawa H, Wittkampf FHM, Pitha JV, Lazzara R, Jackman WM. Comparison of electrode cooling between internal and open irrigation in radiofrequency ablation lesion depth and incidence of thrombus and steam pop. Circulation. 2006;113(1):11-19. doi:10.1161/CIRCULATIONAHA.105.540062 